\title{
KANT EN LA GÉNESIS DE LA CONCEPCIÓN DEL TIEMPO DE SIMONE WEIL
}

\author{
Juan Manuel Ruiz Jiménez* \\ juanmr@uninorte.edu.co
}

RESUMEN La cuestión del tiempo es uno de los principales objetos de estudio que ocuparon a Simone Weil . En efecto, está intensamente presente en su obra desde sus primeros textos hasta sus últimos escritos (1943). La razón es de peso: para esta autora es a través del tiempo que accedemos a la realidad y a toda posibilidad de sentido en sta. Ahora bien, nuestra intención es mostrar que si bien es cierto que la concepción del tiempo de $\mathrm{S}$. Weil, en sus años de madurez, se erige desde una perspectiva espiritualista, mística y religiosa, en su primera época (1925-1931) la filósofa se instala en una ontológica fuertemente influenciada por Kant, que la lleva a restringir lo temporal al marco de la experiencia posible, en el sentido que le da el pensador alemán.

Palabras clave: temporalidad; medir; fenómeno; esquematismo; experiencia

Abstract: The question of time is one of the most important subjects in Simone Weil's philosophy. Indeed, time's issue is intensively present in her works from her earlier texts until her last writings (1943). This can be explained by the fact that, for this author, it is through time that we can access to reality and find any sense into the latter. That being said, our goal is to show that, if certainly it can be affirmed that $\mathrm{S}$. Weil's conception of time in her maturity years is constructed from a spiritual, mystic and religious perspective, at the opposite, in her first period (1925-1931), the philosopher settles her views through an ontology strong influenced by Kant, which conducts her to limited temporal matters into the frame of possible experience, according to the definition of this expression given by the German thinker.

* Universidad del Norte (Colômbia). Artigo recebido em 10/03/2017 e aprovado em 12/05/2017

1 A partir de acá S.Weil. 
Keywords: phenomenology, cartesianism, transcendental, empathy.

La cuestión del tiempo constituye, sin lugar a dudas, una de las principales preocupaciones en el pensamiento de S. Weil. Hay que decir que en sus primeros textos se evidenciaba ya este interés, el cual desembocaría, con el transcurso de los años, en una original concepción del tiempo. Cabe notar sin embargo que esta concepción, como sucede con todo gran pensador, no hubiera sido posible si su reflexión personal no se hubiera visto influenciada desde sus años de juventud por las ideas de grandes filósofos. En el caso de S.Weil, esta siempre se reconoció heredera de Platón ${ }^{1}$, Descartes y Kant ${ }^{2}$. Dicho esto, todo conocedor de la obra de S.Weil sabe que el influjo de otros autores que consideraba ajenos a su línea de pensamiento, como Spinoza y Bergson, también se evidencia en sus reflexiones sobre el tiempo. En este sentido, la intención del presente trabajo es ir a la génesis de la concepción weiliana del tiempo, para poner de manifiesto la que a juicio nuestro fue la influencia filosófica más determinante en los primeros años de trabajo de S.Weil, esto es la de $\mathrm{Kant}^{3}$, y el modo como nuestra autora la asimiló para incorporarla a su propio pensamiento. Realizaremos este bosquejo en dos partes: en la primera, nos centraremos en la hipótesis de Dios como idea reguladora para entender la temporalidad humana en Kant y S.Weil; y en la segunda, destacaremos la influencia del esquematismo kantiano en la idea del tiempo de la joven S. Weil.

\section{I- La hipótesis de la existencia de Dios como idea reguladora para entender la temporalidad humana en Kant y S. Weil}

Desde sus más tiernos años de formación, la joven $\mathrm{S}$. Weil ya tenía claro que no era prudente ni útil preocuparse filosóficamente por la pregunta de la existencia de Dios, razón por la cual decide abstenerse de negarla o afirmarla. En su Lettre au Père Perrin du 14 mai 1942 escribe:

« Desde la adolescencia pensaba que el problema de Dios era un problema cuyos datos faltaban acá abajo (en la tierra) y que el único método acertado

1 Cabe resaltar que, en su última época, es a Platón a quien S. Weil le consagrará la mayor atención. Es con razón que Luc Brisson anota en un artículo del 2013, que incluso en los últimos años de su vida, la filósofa se consagra a trabajar asiduamente a Platón: "sobre el Timeo en Marsella, desde el fin de diciembre de 1941 hasta febrero de 1942; luego en abril de 1942; ella continuará su trabajo en Londres en 1943.” (Brisson 2013, p. 234), Esta y las demás traducciones de las citas son mías.

2 Su compañera de colegio en el Lycée Henri IV y en la École Normale Supérieur, Simone Pétreent, menciona varias veces esta explícita y reivindicada influencia en la obra weiliana a lo largo de la biografía que dedica a Simone Weil. (Pétrement 1973, p.91).

3 Ver a este propósito el artículo de Miklos Vetö "Kantische Themen im Denken der Simone Weil" en el que anota que en su última época $\mathrm{S}$. Weil desplaza y transforma la neutralidad del tiempo kantiano en y hacia una apertura cuya dimensión es ética y religiosa. (Vetö 1985, p.44). 
para evitar resolverlo erróneamente, era no plantearlo, lo que me parecía el mayor mal posible. Así es que no lo planteaba. Yo no afirmaba ni negaba. Me parecía inútil resolver ese problema, puesto que pensaba que estando en este mundo nuestro asunto era adoptar la mejor actitud respecto a los problemas de este mundo, y que esa actitud no dependía de la solución del problema de Dios. » (WEIL 1999, p.768).

La dificultad de la cuestión de la existencia de Dios le parecía exceder sobremanera las capacidades intelectuales del hombre, por lo que resolvió que valía más la pena ocuparse de asuntos más pragmáticos y accesibles. De ahí que su primera filosofía se haya centrado en problemas sobre la percepción, la economía y cuestiones de índole sociopolítica.

Además de esta prudencia respecto a lo infructuoso de asumir un posicionamiento de afirmación o negación con relación a la existencia de Dios, hay que tener en cuenta que Simone Weil establece, en ese momento de su reflexión sobre el tiempo y la naturaleza, un límite claro entre teología y filosofía:

« El instinto popular, en su teología, ha percibido que un ser todopoderoso, para el que todo sería inmediato, es decir, para el que el deseo traería por sí mismo su objeto, no estaría sometido al tiempo: asimismo, en el Paraíso terrestre, no había tiempo, y Adán fue condenado a envejecer y a no ejercer otra cosa que esa potencia indirecta que tiene por nombre trabajo. » (Weil 1988, p. 142-143).

En este extracto S.Weil evoca la cuestión de Dios, pero con el objetivo de evidenciar el reflejo elemental de la antropomorfización de Dios que realiza la imaginación del hombre cuando este se halla aún en el primer estadio de su interpretación del mundo 4 . Para S.Weil, lo útil de tal ejercicio no reside en comprender la temporalidad de ese hipotético Dios -acá la preocupación no es saber si existe o no-, sino la experiencia del tiempo que tiene el ser humano, a la luz de dicha antropomorfización. En efecto, ella aborda ciertamente la relación de Dios con el tiempo, pero lo hace poniendo mucha atención en subrayar que, para considerarla, hay que adoptar el punto de vista del instinto popular en su teología. De cierta manera, la filósofa está diciendo que si se acepta la hipótesis de un Dios todopoderoso - concebido este como un hombre todopoderoso-, habría que imaginarlo como un ser para el que habría un nexo permanente e inmediato entre deseo y objeto. Pero hay más: estos últimos estarían

4 Para profundizar en esta dirección es recomendable dirigirse al reciente artículo de François Marxrer, quien, interpretando a Simone Weil, retoma la perspectiva de Clemente de Alexandría y de Orígenes al decir que "(...) en las corrientes religiosas y la experiencia espiritual de la que atestiguan los paganismos, se podían vislumbrar las semillas del logos, huellas discretas, escondidas, de este Principio del mundo, vestigia de su presencia discernible en todas las manifestaciones de bondad, belleza o verdad que ennoblecían el cosmos y la humanidad (...). Así podía concebirse una relación real, aún escondida, entre la búsqueda religiosa de los paganos, estimulados y orientados por las prescripciones de la conciencia y la Vía única, abierta por el cristianismo." (Marxrer 2012, p. 191). 
fundidos en una misma instancia y en un mismo instante. La idea de S. Weil es transponer esa supuesta temporalidad de la inmediatez, propia del plano divino antropomorfizado, al plano humano, para comprender mejor este último, es decir, el mundo humano, que es lo único que nos es dado. En ese sentido evoca también la hipótesis del paraíso terrestre (surgida del instinto popular en su teología), sin preocuparse de si el paraíso existe o no, pues eso no tiene relevancia para ella en ese momento de su vida intelectual, sino para dar luces sobre el deseo humano. Valiéndose pues de esa idea utópica de un imaginado lugar divino, también este, antropomorfizado, nos dice que para el hombre paradisíaco (al igual que para Dios) no habría distancia ni disociación entre tiempo del deseo y tiempo de la obtención de las cosas deseadas. Es desde esa perspectiva que S. Weil nos muestra que para el instinto popular en su teología, el tiempo es experimentado como una pena a padecer por los seres humanos, o mejor, un castigo. El tiempo traduciría una caída desde la perfección de ese lugar utópico (un mundo sin tiempo) a la imperfección (un mundo temporal). El trabajo y el envejecimiento serían pesos que el hombre excluido del paraíso deberá cargar durante toda su vida. Excluido del Edén, el hombre envejecerá bajo el influjo del tiempo, y al término de su decrepitud morirá en este. Así, el trabajo -la relación indirecta entre deseo y objeto-, y el desgaste del cuerpo -daños, enfermedad y envejecimiento- son todos signos de impotencia ${ }^{5}$. La muerte, el término de la vida, traduce una condición de imperfección y por ende no es atribuible a Dios, siempre que se suponga que este exista, y que sea perfecto. Dios, de existir, o de ser la perfección suprema de lo existente, no viviría en el tiempo. Decir que ese ser perfecto no puede estar sometido al tiempo significa que este último es una imperfección que no concierne sino a criaturas, o en otras palabras, a seres imperfectos cuya potencia es finita, tales como nosotros $^{6}$. Dicho lo anterior, $\mathrm{S}$. Weil señalará en otro texto de la misma época que el hombre, desde esa misma antropomorfización que proyecta en la

5 En su libro "La métaphysique religieuse de Simone Weil", M Vetö pone de manifiesto que desde 1926 Simone Weil ya concebía el tiempo como mediación, es decir, como un puente irreductible que distancia al yo que desea en el momento presente del yo que se proyecta en el futuro. Vetö indica con razón que para la filósofa francesa, la determinación del tiempo aparecía ya, desde sus primeros años de reflexión, como la marca de la impotencia humana, ya que el tiempo obliga al individuo a pasar a cada instante por etapas intermedias antes de la obtención del objeto o estado deseados. En otras palabras, el tiempo obliga al hombre a no poder ser u obtener nada en la inmediatez. (Vetö 1997, p.105.)

6 En este sentido, Miklos Vetö le da énfasis a las observaciones que hizo S. Weil en sus años como obrera, plasmadas particularmente en su Journal d'Usine. La tragedia de la vida del obrero no calificado no se limita a la precariedad de sus ingresos, sino también al tiempo infernal que padece en la fábrica, ya que la monotonía del trabajo mecanizado destruye toda posibilidad de constituir la única forma de unidad que es posible en la realidad humana, y que no es otra que la de lograr el contacto entre presente y futuro gracias a la labor del pensamiento. M Vetö indica así que si ciertamente es imposible abolir la necesidad de las determinaciones del tiempo, la monotonía del trabajo fabril oprime a tal punto al obrero, que lo hunde en un presente del que no logra escapar. Vetö dirá que "cuando está obligado a repetir el mismo movimiento en los minutos que siguen, él ya no tiene el poder sobre el futuro, él está reducido al presente.” (Vetö 1997, p.106.) 
idea de Dios, ha creído ver una perfección en sí mismo, o mejor, un signo de la presencia de lo divino en su alma:

« (...) como el orden de los eventos no depende del hombre como sí depende la obra de arte, la prueba físico-teológica de la existencia de Dios, sacada de la perfección del Universo, toma aquí toda su fuerza ; y la objeción sacada de las imperfecciones del universo es fácilmente destrozada por la ignorancia del hombre; puesto que es verdad que entre más somos libres, más pensamos a partir de todas las cosas y más el universo es perfecto, y para un ser perfecto y libre, es rigurosamente verdadero decir que el universo no puede ser sino perfecto. » (Weil 1988, p. 300).

S.Weil se detiene en este pensamiento común de la teología más elemental, según la cual, el sentimiento de nuestra libertad nos parece una perfección de nuestra naturaleza humana. En efecto, entre más estemos sometidos a plegarnos a la necesidad, menos potencia tendremos. Y en este orden de ideas, se puede afirmar que el tiempo es por excelencia, en la medida en que el orden de los eventos no depende de nosotros, la instancia más antagónica a nuestra libertad. El tiempo, concebido como ese orden en el cual fluyen los eventos, sería entonces contrario a esa única perfección que estaría en nosotros: nuestra libertad. El tiempo, concebido así como la encarnación misma de la necesidad, sería el (otro) de nuestra libertad. Por consiguiente, en la medida en que uno concibe un ser perfecto (Dios), lo más lógico sería estimar que él no puede padecer como nosotros ese tiempo que nos somete. Podemos decir que S. Weil resume así los atributos temporales de ese Dios hipotético: 1. es porque él es absolutamente libre que no puede estar en el tiempo; 2. Es porque él es absolutamente libre que nada en él es tocado por la mediación temporal entre deseos y objetos (puesto que es necesario un momento para desear un objeto y luego un momento diferente para obtenerlo). Un ser perfectamente libre es entonces necesariamente, siguiendo esta lógica, perfectamente ajeno al tiempo y por ende al deseo (y aquí nos encontramos con un análisis eminentemente spinozista, tal como figura en la Ética: el hombre no puede no desear y desea lo que aparentemente puede aumentar su potencia. Dios es infinita y eternamente potente y por ende no desea). Dicho lo anterior, creemos poder emitir la hipótesis siguiente: la prudencia con la cual S.Weil se posiciona frente a la idea del tiempo con relación a un eventual Dios creador del universo, se debe a la influencia que ejercieron en ella las reflexiones que a ese respecto hizo Kant en la Crítica de la Razón Pura. Recordemos que en esta obra Kant evoca a Dios, pero no se consagra ni a negar su existencia ni a afirmarla (en esto S. Weil parece haberlo imitado), como en cambio sí sucede y de manera muy explícita en la Crítica de la Razón Práctica, a saber, como raíz primera de la consciencia del deber y de la ley moral subsecuente. En efecto, en la Crítica de la Razón Pura, 
Kant intentó asumir la posición que le pareció ser la más conforme posible al nivel de los límites de nuestras facultades intelectuales y sensibles, cuando al conocimiento de los fenómenos se refiere.

En este sentido, y esto es de vital importancia para poder entender la evolución de la concepción weiliana del tiempo que se desarrollará en el resto de su obra, S.Weil evoca a Dios en lo que compete a la reflexión sobre el tiempo y los fenómenos, de manera análoga a la de Kant en la Estética trascendental, es decir, como hipótesis de trabajo para comprender la efectividad del tiempo en el mundo humano ${ }^{7}$, o en otras palabras, como idea reguladora para concebir la temporalidad del hombre. No es un azar si S. Weil se refiere al pensamiento popular, en su teología, a la manera de Kant a propósito de la teología natural. Lo cito:

«En la teología natural, en la que uno se forja el pensamiento de un objeto que no solamente no puede en nada ser para nosotros un objeto de la intuición, sino que no puede absolutamente ser por sí mismo un objeto de la intuición sensible, uno vigila escrupulosamente a eliminar las condiciones del espacio y del tiempo del conjunto de la intuición que le es propia (puesto que todo su conocimiento debe ser intuición y no pensamiento, el cual presenta siempre límites). ¿Pero con qué derecho puede uno realizar este procedimiento, cuando uno ha previamente hecho de esos dos elementos formas de las cosas en sí, y más precisamente formas tales que ellas subsisten como condiciones de la existencia de cosas a priori, incluso cuando se hubiere suprimido las cosas mismas? Puesto que, en tanto que condiciones de toda existencia en general, ellas deberían también ser condiciones de la existencia de Dios. » (Kant 2001, p. 140-141).

Kant nos dice ciertamente que en la teología natural se puede pensar a Dios. Sin embargo, de existir, teniendo en cuenta los límites de nuestras facultades intelectuales, no podríamos en lo absoluto conocerlo, puesto que él no sería objeto de intuición intelectual. Ahora bien, según Kant, solamente la intuición intelectual (a distinguir de la intuición empírica) es conocimiento objetivo de las cosas en sí o noúmenos, la cual no le es dada al hombre. Por otro lado, al concebir un tal Ser supremo, lo imaginamos necesariamente omnisciente, y

7 M. Gabellieri irá hasta a afirmar en este sentido que la joven S.Weil se limita a hacer alusión a Dios únicamente a título de idea, es decir, como un Ser absoluto respecto al cual pueden ser mejor puestas en evidencia las limitaciones de nuestra percepción humana: « (...) es precisamente mediante la doble trascendencia de la esencia sobre la existencia y de la libertad sobre la esencia, que S. Weil define a Dios, a partir de Le beau et le bien. Pero en ese estadio de su reflexión, este último no puede ser más que una idea. Dios es esa plenitud y esa libertad abstractas que yo pienso cuando formulo en idea un ser cuya esencia coincidiría con la existencia y el querer, sin separación consigo mismo. No es lo que sucede con el hombre, ser que no cesa de experimentar esa separación en sí mismo y en el mundo, pero que parece tener por vocación unir mediante el pensamiento la esencia y la existencia, cuando precisamente su propia identidad ontológica parece ser su disyunción misma. » (Gabellieri 2003, p. 44). 
suponemos, por consiguiente, que para él toda cosa existente es objeto de intuición intelectual. Así, el conocimiento de Dios sería intuición intelectual — por consiguiente inmediata - y no empírica. Dicho de otro modo, su pensamiento no estaría mediado. Más aún: Dios no tendría pensamiento alguno puesto que todo pensamiento está limitado por el sometimiento que imponen el tiempo y el espacio, y a través de los cuales (en tanto que intuiciones a priori) uno percibe todo objeto. El conocimiento de Dios no podría verse sometido al abismo irreductible que se establece siempre entre sujeto y objeto. De esta forma, Kant nos muestra que el tiempo y el espacio no pueden ser substancias o accidentes en sí, porque son las condiciones de posibilidad humanas de toda experiencia posible, y no las condiciones de posibilidad del ser de las cosas, o en otras palabras, de las cosas en sí. Se concluye así que el espacio y el tiempo no pueden condicionar lo incondicionado, a saber el Ser absolutamente libre (a Dios). Desde esta misma perspectiva, no podrían condicionar el conocimiento que él tendría de las cosas en sí. Más todavía: Kant señala que de aceptar la idea de la existencia de Dios, en este el conocimiento sería originario y no receptivo, como lo indica más adelante la Estética trascendental:

« No queda más, si uno no quiere hacer formas objetivas de todas las cosas, que hacer de ellas formas subjetivas de nuestro modo de intuición externo tanto como interno, modo que es llamado sensible porque no es originario, es decir, que por él la existencia misma del objeto de la intuición sea dado (modo que, hasta donde podemos ver, no puede conferírsele sino al Ser supremo), pero que está bajo la dependencia de la existencia del objeto y no es por consiguiente posible sino en la medida en que la capacidad representativa del sujeto se ve afectada. » (Kant 2001, p. 141).

Kant buscaba establecer así que el ser humano está sometido a la sensibilidad, es decir, que es receptivo a los objetos. Esto significa que la percepción que tenemos de nuestra propia existencia se presenta, ella también, bajo forma de objeto. En resumen, para Kant toda cosa nos es dada, y nada nos afecta a no ser que, no nos sea previamente dado. Pero no somos en nada los autores, ni de los objetos percibidos, ni de las formas propias de nuestro modo de intuir (a saber, del tiempo y del espacio). La naturaleza humana es enteramente dependiente, todo se juega para nosotros a través de una separación entre sujeto y objeto, y por consiguiente estamos integralmente mediados. En síntesis, tenemos que habérnoslas con lo que ya está ahí (nuestra propia existencia y la posible interrelación entre nosotros y las cosas percibidas), pero no le damos el origen a ello:

« [...] el modo de intuición en el espacio y el tiempo [...] no obstante no cesa, a pesar de ese alcance universal, de estar ligado a la sensibilidad, precisamente porque es derivado (intuitus derivativus), no originario (intuitus ori- 
ginarius), y por consiguiente no está en una intuición intelectual, como la que [...] parece corresponder únicamente al Ser supremo, pero jamás a un ser dependiente por su existencia como por lo que concierne a su intuición (que [...] determina su existencia en relación a objetos dados). Por lo tanto, esta última observación debe ser tenida en cuenta, respecto a nuestra teoría estética, únicamente como una aclaración, pero no como una prueba. »(Kant 2001, p.141).

Nos parece pues evidente que S. Weil adopta este mismo punto de vista, es decir que ella no considera a Dios sino como hipótesis para pensar la posición de la teología popular (en esto equivalente a la teología natural según Kant) con el fin de aprehender mejor el problema del tiempo y de la mediación entre el hombre y los objetos, pero no como una prueba de la existencia de Dios. $\mathrm{S}$.Weil, pensando en la situación post-paradisíaca que nos es dada, sigue a Kant para dilucidar la naturaleza de la condición humana, en la cual el hombre debe ejercer un esfuerzo (y por supuesto un trabajo) para poner en relación sus deseos con los objetos. En resumen, para S. Weil como para el pensador alemán, en la experiencia temporal del ser humano nada es inmediato.

\section{II- La influencia del esquematismo kantiano en la idea del tiempo de la joven S.Weil}

Retomemos nuestro planteamiento: si en este primer periodo de su pensamiento, S.Weil se sirve de la hipótesis de la existencia de Dios, es para cimentar una idea límite que le permita aprehender mejor la especificidad de la temporalidad humana. Y esto, como lo dijimos, siguiendo a Kant. Este último echó mano de dicha hipótesis para establecer la inmediatez de la intelección de la que se supone estaría dotado ese Ser supremo y perfecto, respecto a la cual se puede concebir mejor la imperfecta, mediada y limitada aprehensión humana de los fenómenos, y de forma general nuestra intuición espaciotemporal. Con esta consideración hecha, podemos ahora asir con un poco más de claridad la manera como la filósofa francesa concibe el tiempo y el espacio humanos. Podemos comenzar por decir que para S. Weil hay una primacía del tiempo sobre el espacio, la extensión siendo para la pensadora francesa una derivación del tiempo. Vayamos a uno de sus textos sobre el tiempo y el esquematismo:

« La distancia es una idea que pertenece menos al espacio que al tiempo, aunque únicamente la extensión nos impone, entre nuestro objeto y nosotros, una distancia; de ahí esta fórmula asombrosa " el tiempo es la medida del espacio ", o esta otra fórmula, en el fondo, equivalente: "El número es el esquema de la cantidad ". ${ }^{8}$ (Weil 1988, p. 152-152). 
Estas dos expresiones hacen alusión a la disposición cognitiva entre tiempo y espacio que se presenta en la mente humana, ya que señalan que en nuestro espíritu hay anterioridad en la estructuración del primero respecto a la del segundo. La primera cita, que es de Lagneau, es mucho más explícita que la de Kant (la segunda). Pero en términos generales las dos expresiones significan que, para un espíritu humano, la inteligibilidad del tiempo no solamente precede, sino que da su coherencia estructural a la que tenemos del espacio. Señalemos un aspecto muy importante que sin embargo, por el momento, dejaremos de lado a pesar de su importancia, a saber que S. Weil, al adherir al punto de vista de Kant, según el cual la separación en la extensión está derivada de una capacidad a priori de abrazar el tiempo, nos da a entender que este orden de cosas está ligado al ámbito del nexo entre sujeto y objeto ${ }^{9}$. En esto, en nuestra opinión, S.Weil acertó, puesto que si entre nosotros y el objeto constatamos una distancia fáctica en la extensión, es solamente porque hay en nosotros una capacidad para comprender una separación todavía más fundamental: la división temporal entre el antes del sujeto desposeído fundamentalmente del objeto, y el eventual después que implica un acercamiento, o mejor, un alcanzar el objeto en el caso límite. Esta observación es fundamental e introduce ya en el primer periodo del pensamiento de $\mathrm{S}$. Weil el problema del objeto en relación al tiempo y al espacio.

Volvamos pues a la expresión de Lagneau, la cual nos indica que si el tiempo mide el espacio, esto quiere decir que el primero es criterio y unidad de medida de lo que es medido (el espacio). Pero la expresión de Kant es menos evidente si no sabemos lo que el término esquema significa.

Detengámonos entonces aquí a recordar lo que es la noción de esquema en Kant a la que hace referencia S. Weil, dirigiéndonos directamente a la Crítica de la Razón Pura, con el fin de penetrar mejor la reflexión de la filósofa francesa:

« [...], los conceptos puros del entendimiento, si uno los compara a las intuiciones empíricas (o incluso, de forma general, sensibles), les son totalmente heterogéneas y no pueden jamás hallarse en intuición alguna. [...] es claro que

1, «Del esquematismo de los conceptos puros del entendimiento » (Weil 1988, p. 152-152).

9 M. Vetö muestra con acuidad que Simone Weil tenía claro que el tiempo, a pesar de sus determinaciones, es también el verdadero horizonte de nuestra libertad, ya que en todo instante presente el yo se ve interpelado por móviles, es decir, por deseos que lo conminan a buscar opciones para alcanzar sus fines. Ahora bien, es en esta expansión de sí hacia el futuro, que el yo busca lo que no tiene aún, y de esta manera se busca a sí mismo a partir de lo que no es o no tiene todavía. M. Vetö muestra así que es a través de esta autonomía del individuo en su relación con el futuro que se opera una transformación de la concepción kantiana del tiempo en Simone Weil. En efecto, para ella, estar reducidos a la mera receptividad del tiempo fenoménico, tal y como la entiende Kant, es apenas la antesala del yo. Pues es solamente en la búsqueda de lo que desea poseer, que el yo se mueve hacia a una transformación de sí mismo, necesaria para la construcción de su identidad individual. (Vetö 1997, pp.113-114.) 
debe haber un tercer término, que debe mantener una relación de homogeneidad por un lado con la categoría, por el otro con el fenómeno, y hacer posible la aplicación de aquella a este. Esta representación mediadora (desprovista de todo elemento empírico) es sin embargo por un lado intelectual, por el otro sensible. Tal es el esquema transcendental. » (Kant 2001, p. 224-225).

El esquema es entonces el puente entre la instancia de nuestro espíritu ligada al entendimiento puro (se trata de la categoría kantiana, o concepto puro, el cual es dado a priori, es decir, antes de toda experiencia) y aquella que está relacionada a la sensibilidad (lo que para Kant es toda intuición experimentada a posteriori del suelo constituido por las categorías del entendimiento y las intuiciones puras que son el espacio y el tiempo, y por ende posteriormente al conjunto de nuestras facultades dadas antes de toda experiencia).

Recordémoslo, para Kant el esquema no es exactamente el doble del concepto puro del entendimiento (o categoría), sino la forma bajo la cual este último puede ser aplicado en el ámbito de los fenómenos sensibles:

« Esa condición formal y pura de la sensibilidad, a la que el concepto del entendimiento se halla restringido en su uso, lo llamaremos el esquema de ese concepto del entendimiento, y el método que practica el entendimiento con esos esquemas, lo llamaremos el esquematismo del entendimiento puro. » (Kant 2001, p.225).

El esquema es por consiguiente la puesta en práctica del concepto puro cuando entra en relación con el ámbito fenoménico. Él es una condición formal, o en otras palabras, una condición que limita y determina la acción del concepto puro. El esquema es así una regla que filtra y restringe la acción del concepto puro, es decir en su uso, pero solamente en el uso, porque en el ámbito del entendimiento puro la categoría conserva todo el alcance de sus posibilidades. El esquema es por consiguiente una verdadera mediación ${ }^{10}$ entre la capacidad humana de conocer y la efectividad de la experiencia ${ }^{11}$.

10 A este propósito vale la pena recordar los términos bajo los cuales M. Casper se refiere a la especificidad weliana de la mediación tiempo-trabajo: « S.Weil (...) intenta (...) - teniendo en cuenta, tal parece, el capítulo sobre el esquematismo de la Crítica de la razón pura - poner en relación el tiempo a la situación del hombre entre materialidad y razón. Este lugar de intermediario acarrea al hombre su alienación, es decir la imposibilidad de ser inmediatamente. El tiempo se revela así ser « la ley mediante la cual nada para mí es inmediato ». En este sentido, el tiempo representa la puesta en cuestión de mi « potencia sin límites » y en últimas termina por ser « una existencia extranjera con la que me choco ». Pero la mediación, que, para Kant, se opera en el esquematismo de los conceptos puros de la razón, restringidos por la sensibilidad, se opera, según S.Weil, por el trabajo. Solamente el trabajo es esta mediación gracias a la cual el presente está enlazado al futuro, el « lo que soy » a « lo que yo quiero ser ». (...) Esta comprensión del tiempo que parte de la pregunta concerniente a la condición bajo la cual yo existo y que se sitúa alrededor del fenómeno del trabajo, se halla hasta en las obras más tardías. " (Casper 1985, p. 242-243).

11 Señalemos a este respecto la interesante relación que establece M. Chenavier entre la noción kantiana de esquema y la del trabajo en S.Weil: « El trabajo como necesidad no está deducido de las formas a priori del espacio y el tiempo. Él hace experimentar la existencia del mundo mediante la necesidad de plegarse a las formas de la existencia que son el espacio y el tiempo. Si la significación del esquema kantiano es, 
Por otro lado, si Kant afirma que el esquematismo es el método que practica el entendimiento con sus esquemas, se puede afirmar que antes de la puesta en práctica de ese método, el esquema consistiría en la disponibilidad latente del método, en la mente, para aplicar las categorías del entendimiento a los fenómenos ${ }^{12}$.

Ahora bien, debemos detenernos aquí, pues por el momento solamente hemos elucidado cuál es la función del esquema (a saber establecer un puente entre las categorías del entendimiento y la percepción de los fenómenos), y no todavía lo que es verdaderamente su naturaleza. Debemos así, en todo rigor, aclarar cuál es esta, puesto que es problemático aceptar una instancia a medio camino entre nuestras intuiciones a priori (dadas previamente a la experiencia) y nuestras intuiciones a posteriori (dadas mediante la experiencia sensible). Vayamos al texto de Kant:

«El esquema es siempre, en sí mismo, un simple producto de la imaginación. Pero dado que la síntesis que realiza esta última no tiene por objetivo ninguna intuición particular, sino solamente la unidad en la determinación de la sensibilidad, el esquema debe, sin embargo, ser distinguido de la imagen. Así, cuando yo sitúo cinco puntos el uno detrás del otro: ....., es esta una imagen del número cinco. Pero, cuando yo me limito a pensar un número en general, que puede entonces ser cinco o cien, este pensamiento es más la representación de un método para representar, conformemente a cierto concepto, una multiplicidad (por ejemplo mil) en una imagen, que esta imagen misma -la cual, en este último caso, yo podría difícilmente abarcar con la mirada y comparar al concepto. Es entonces esa representación de un método general de (...) la imaginación para procurar a un (...) concepto su imagen que yo llamo el esquema correspondiente a ese concepto. (Kant 2001, p. 225-226).

En esta definición de Kant hay un problema, porque nos dice que el esquema es al mismo tiempo un producto de la imaginación, por consiguiente una imagen, y otra cosa que difiere de una simple imagen. El esquema sería entonces una imagen que no es como las otras en la medida en que se distingue de ellas por su poder singular de organizar las imágenes particulares; es lo que deja entender Kant cuando lo define como a una representación de un método para representar. Ahora bien, su poder de organizar las imágenes es conforme al concepto al que el esquema está correlacionado. En este orden de

finalmente, hacer posible la experiencia de la exterioridad, el uso de la noción de esquematismo conviene perfectamente al rol que juega el trabajo. » (Chenavier 2001, p. 109).

12 Nuestra interpretación del esquema kantiano nos parece diferir ligeramente de la de M. Chenavier. En efecto, este último subraya: « Determinación del tiempo, pero no representable como figura particular, el esquema no puede caer bajo el sentido, él es un método. " (Chenavier 2001, p. 112). Vemos que para M. Chenavier el esquema es un método en sí mismo, mientras que para nosotros, se trata de una condición de disponibilidad latente del método del que se sirve el entendimiento para aplicar sus categorías a los fenómenos. Porque nosotros creemos que para Kant el método es el esquematismo y no el esquema en sí mismo. 
ideas, ese poder organizador no se aplica a cualquier imagen, sino únicamente a aquellas que son susceptibles de ser organizadas bajo su marco. Dicho marco, capacidad o poder organizador, es transmitido, comunicado por el concepto al esquema. Es así como el esquema de la multiplicidad o del número general va a ocuparse de organizar las imágenes relativas a la representación de los números particulares. De este modo, Kant define el esquema como una representación de un método general, y no como una imagen particular. Si el esquema es, según Kant, la representación de un método, es justo decir que él es también un modelo bajo el cual están subsumidas las imágenes particulares. El modelo establece la regla de universalidad que estructura toda posible comprensión de una imagen particular. Ahora bien, esta regla es homogénea al concepto puro, y al mismo tiempo lo es respecto a las imágenes particulares percibidas o simplemente imaginadas. No obstante, el esquema sitúa y delimita, entre la multiplicidad indefinida de las imágenes particulares, lo que está conforme o no con la regla. Es por esta razón que Kant subraya que el esquema no es una imagen cualquiera, sino que resulta, no obstante, de la imaginación. El esquema sería, así, ciertamente una imagen, pero una imagen-regla o imagenmodelo que incorpora en sí la regla proveniente del concepto puro del entendimiento. El esquema no es el concepto mismo, pues esto sería decir que el concepto percibe los fenómenos, o los elementos que permiten su percepción (tiempo y espacio en tanto intuiciones puras o formas puras de la sensibilidad). El esquema es más bien un instrumento cognitivo de orientación al servicio del concepto puro, que le permite filtrar a este, a partir de la unidad de la regla, tanto lo que se acerca a ella (por ejemplo un triángulo rectángulo dado que uno perciba respecto a la imagen-modelo del triángulo que uno no verá jamás) como lo que se aleja de ella (por ejemplo la percepción de otra figura, como la del cuadrado). Le permite entonces al concepto puro asir la multiplicidad de las imágenes, tanto por identidad como por diferencia, y por consiguiente, el esquema comparte con la categoría una permanencia que le permite a este navegar en el océano indefinido de lo múltiple. Ahora bien, esta permanencia tiene una relación necesaria con la noción de unidad. Sin embargo, para comprender bien este nexo con la unidad, debemos primero ponerle atención a una sutilidad en lo que concierne a los esquemas kantianos, pues Kant establece una distinción entre dos tipos de esquemas: el de los conceptos sensibles y el de los conceptos puros del entendimiento. Veamos primero lo que nos dice en lo que concierne al esquema de los conceptos sensibles:

« [...] podemos decir que la imagen es un producto del poder empírico de la imaginación productiva, que el esquema de los conceptos sensibles (como (...) figuras en el espacio) es un producto y por así decirlo un monograma de la imaginación pura a priori con la ayuda del cual y según el cual solamente 
las imágenes llegan a ser posibles, pero de tal manera que estas deben siempre estar atadas al concepto únicamente por medio del esquema hacia el que ellas hacen signo, y esto sin ser en sí mismas enteramente congruentes con éste. » (Kant 2001, p. 226).

Lo que resulta claro de esta afirmación es que en el caso de los esquemas de los conceptos sensibles hay una estructuración ramificada en tres elementos: en una extremidad el concepto, en la otra la imagen, y entre las dos el esquema que aplica, en su relación con las imágenes, el método en conformidad con la regla del concepto. Miremos ahora lo que dice Kant sobre los esquemas de los conceptos puros del entendimiento:

«Al contrario, el esquema de un concepto puro del entendimiento es algo que no puede ser remitido a ninguna imagen : él no es de hecho sino la síntesis pura realizada conformemente a una regla de la unidad a partir de conceptos en general, regla que está expresada por la categoría, y él es un producto trascendental de la imaginación que concierne a la determinación del sentido interno, en general, según las condiciones de su forma (el tiempo) relativamente a todas las representaciones, en tanto que ellas deben articularse a priori en un concepto conformemente a la unidad de la apercepción. » (Kant 2001, p. 227).

Vemos que acá la estructura es igualmente tripartita, pero con un elemento fundamentalmente diferente: tenemos en una extremidad el concepto puro o categoría que proyecta una regla (como en el caso del concepto sensible), en la otra extremidad el sentido interno, que a partir de las condiciones de su forma proyecta una determinación dada, y entre las dos tenemos el esquema que establece la síntesis de ambas. Así, entendemos por qué el esquema del entendimiento puro es absolutamente trascendental, puesto que este no ata en lo absoluto imágenes particulares a conceptos, sino conceptos a la forma del sentido interno, es decir, al tiempo mismo. Podemos solamente ver que los dos tipos de esquema han surgido de la imaginación, pero, mientras que el de los conceptos sensibles apunta a atar los conceptos a imágenes particulares, el de los conceptos puros apunta a atar los conceptos a lo que nos permite aprehender el conjunto de todas las representaciones en general, en una unidad estructurante donde ellas se ven puestas en relación. Y esta unidad estructurante (que instaura un sentido primordial ${ }^{13}$ en la inteligibilidad del hombre) nos es dada por el sentido interno (cuya forma es el tiempo), el cual abre simultáneamente la apercepción (la percepción de sí). Comprendemos ahora por qué, en su concepción kantiana, la joven $\mathrm{S}$. Weil afirmaba que es la inteligibilidad del tiempo la que permite la del espacio: se debe a que el espacio no puede ser comprendido sino porque nuestra intelección del tiempo nos permite establecer 
una unidad que se aplica en segunda instancia al espacio. Para S. Weil, como para Kant, nuestros conceptos sensibles no pueden tener sentido sino porque en nosotros el esquema del entendimiento puro permite estructurar la unidad fundamental y necesaria para que los esquemas sensibles, que apuntan hacia los casos particulares, puedan desplegarse. En ese sentido podemos afirmar que en Kant la naturaleza y función de los esquemas establecen una inteligibilidad fundamental del tiempo que nos es dada antes de toda otra inteligibilidad perceptiva, incluso la del espacio. No olvidemos, además, que para Kant la intuición pura del tiempo, que es la forma de nuestro sentido interno, es aquella que nos da acceso a la percepción de la unidad que nos constituye a nosotros mismos y que establece la consciencia de nuestra propia existencia, o dicho de otro modo, de la apercepción :

« Los esquemas no son (...) otra cosa más que determinaciones a priori del tiempo según unas reglas, y esas determinaciones se remiten, siguiendo el orden de las categorías, a la serie del tiempo, el contenido del tiempo, (...) el orden del tiempo y en fin al conjunto del tiempo relativamente a todos los objetos posibles. (...) el esquematismo del entendimiento, por la intermediación de la síntesis trascendental de la imaginación, no apunta a otra cosa más que a la unidad de todo lo diverso de la intuición en el sentido interno, y así, indirectamente, a la unidad de la apercepción como función que corresponde al sentido interno (a una receptividad). Los esquemas de los conceptos (...) puros del entendimiento son pues las verdaderas y únicas condiciones (...) que permiten procurar a estos una relación a objetos, por consiguiente una significación, y las categorías no tienen así, finalmente, otro uso que no sea su posible uso empírico, o bien ellas sirven simplemente a someter, con la ayuda de los principios de la unidad necesaria a priori (en virtud de la unificación necesaria de toda consciencia en una apercepción originaria), fenómenos a reglas generales de síntesis y a volverlas con ello susceptibles de presentar el nexo continuo que es constitutivo de una experiencia. » (Kant 2001, p. 229).

Ahora que hemos allanado suficientemente el problema del esquematismo, podemos tener en mente que para Kant la inteligibilidad del tiempo tiene, en las operaciones intelectuales del ser humano, una preeminencia sobre la del espacio. En este punto es necesario remitirnos a una observación crucial que hace $\mathrm{S}$. Weil respecto a la concepción kantiana del tiempo y el espacio, que nos permitirá esclarecer su propio pensamiento:

« La filosofía (teórica) de Kant no es otra cosa que una meditación sobre el tiempo; luego él ha hallado, pero sin haberlo planeado, la extensión. » (Weil 1988, p. 124).

A primera vista todo parecería mostrar que, según S. Weil, la preocupación del espacio fue para Kant una preocupación derivada, espontánea y casi des- 
prevenida que se desprendió de la del tiempo. ¿Pero es solamente esto lo que se debe interpretar a partir de esa observación de S.Weil? ¿No es acaso una delicada manera de indicar que el orden en el cual Kant consideró el problema del tiempo, antes que el del espacio, significa precisamente que entre las dos instancias existe una jerarquía cognitiva? ¿Debemos leer que ese orden expresa precisamente el hecho de que para Kant la intelección del tiempo precede estructuralmente a la del espacio, como lo vimos a partir del problema abordado del esquematismo? Nuestra interpretación es que, justamente, para S. Weil, esta preeminencia se da en la comprensión humana de la realidad.

Es ahora que, teniendo en mente estos interrogantes y tras haber dilucidado la cuestión del esquematismo kantiano, debemos retornar a las dos citas hechas por S. Weil para comprenderlas plenamente: la de Lagneau y la de $\mathrm{Kant}^{14}$. La filósofa ve perfectamente el problema de la relación íntima que mantienen el tiempo y el espacio en el espíritu del hombre. Ella concibe, lo hemos visto, como Kant y Lagneau, que el tiempo es la medida del espacio. Y es acá, para terminar nuestro bosquejo, en donde debemos tocar un último aspecto implícito que nos permitirá poner de manifiesto la perspectiva enteramente kantiana de la joven S.Weil.

En ese par de citas, S. Weil no alude al otro lado de esta reflexión sobre el tiempo como medida del espacio, o en todo caso, por lo menos no explícitamente: a través de esas dos citas S. Weil señala que ciertamente aprehendemos la inteligibilidad del tiempo antes que la del espacio. Ahora bien, aunque sin explicitarlo, S.Weil consideraba que es justamente gracias a la intuición que tenemos del espacio que podemos representarnos el tiempo. ¿Por qué estamos tan seguros de esta afirmación? Porque es difícil creer que S.Weil no hubiera contemplado este aspecto, dado que Lagneau y Kant lo habían hecho y porque $\mathrm{S}$. Weil conocía perfectamente sus trabajos ${ }^{15}$. Por un lado, sabemos que su maestro Alain consagró buena parte de sus cursos a transmitir a sus estudiantes la gran influencia que ejerció en él la filosofía de la percepción de su maestro Lagneau. Además, en lo que concierne a este, el equipo de las Euvres Complètes de S.Weil nos muestra que, en particular, la frase de Lagneau citada por S.Weil, de la que nos estamos ocupando acá, tiene como complemento una proposición que evoca con énfasis este aspecto señalado:

«El tiempo medida del espacio, el espacio representación del tiempo. » (Weil 1988, p. 152).

Ahora bien, no solamente podemos suponer que S. Weil conocía la conti-

14 Recordemos que Lagneau sostenía que el tiempo es la medida del espacio; y que para Kant el número es el esquema de la cantidad (Weil 1988, p. 152-152).

15 Ver las constantes alusiones en los cursos dictados por la filósofa en WEIL (Simone), Leçons de philosophie de Simone Weil, (Roanne 1933-1934), Paris: Plon, 1989. 
nuación de esta frase de Lagneau, sino también la concepción casi idéntica de Kant según la cual el hombre, no pudiendo representarse el tiempo mediante este mismo, recurre a la imagen espacial de una línea infinita. Esta concepción figura en la Crítica (obra que S. Weil conocía a la perfección), e intentaremos a continuación exponerlo someramente. Primero que todo recordemos que para Kant, el tiempo, como el espacio, no existen en sí:

« [...] el espacio y el tiempo [...] no pueden, como fenómenos, existir en sí, sino solamente en nosotros. »(Kant 2001, p. 133).

En efecto, el filósofo alemán sostiene que el tiempo y el espacio aparecen como las dos formas de la intuición. De hecho, para demostrarlo, Kant señala que la noción de infinitud no puede aplicarse al tiempo. Efectivamente, en el sistema kantiano, la experiencia nos proporciona fenómenos que podemos solamente intuir mediante el espacio -como forma de los fenómenos de los sentidos externos (Kant 2001, p. 123) - y el tiempo; dado que tiempo y espacio son considerados como nuestras dos intuiciones puras (es decir hallándose en nosotros a priori) a través de las cuales todos los otros fenómenos son susceptibles de ser experimentados, y por ende conocidos en su calidad de fenómenos, y no en sí. Dicho esto, si el espacio nos permite acceder a las formas de los fenómenos gracias a nuestros sentidos externos, por lo que compete al tiempo, no se trata en lo más mínimo de una intuición que nos abriría el acceso a fenómenos en su carácter de figura o de tamaño, sino que permite aprehender las relaciones recíprocas que tienen en nosotros nuestras representaciones:

« El tiempo no es otra cosa que la forma del sentido interno, es decir la intuición que tenemos de nosotros mismos y de nuestro estado interior. Porque el tiempo no puede ser una determinación de los fenómenos exteriores: él no pertenece ni a una figura, ni a una posición, etc; al contrario, él determina la relación de las representaciones en nuestro estado interno. Y es precisamente debido a que esta intuición interna no proporciona ninguna figura, que solemos vernos en la necesidad de buscar contrarrestar esta carencia mediante analogías y que nos representamos la sucesión del tiempo mediante una línea prolongada y al infinito, en la que lo diverso constituye una serie que no posee más que una dimensión, y concluimos que las propiedades de esta línea coinciden con todas las propiedades del tiempo, con excepción que las partes de la primera son simultáneas, mientras que las de la segunda son siempre sucesivas. » (Kant 2001, p. 128).

La idea de la infinitud no es pues, en Kant, más que el reflejo precipitado de transponer la inteligibilidad de lo espacial sobre lo temporal. El tiempo nos parece formar una línea porque en la medida en que constituye el asiento perceptivo de los momentos, experimentamos la estructuración de una serie de eventos que nos permite desprender el antes y el después de manera sucesiva, 
(es decir que una cosa no puede ser al mismo tiempo lo que ella es y su contrario), sino que puede mostrarnos la contradicción por medio de la sucesión:

« Es solamente en el tiempo que dos determinaciones contradictoriamente opuestas pueden hallarse en una cosa, a saber de forma sucesiva. » (Kant 2001, p. 127).

Kant toca acá a la razón fundamental de dicho reflejo de transposición, a saber el hecho de que la representación formal del tiempo no puede hacerse visible sino mediante la espacialización de una línea que se supone está extendida al infinito $^{16}$; evidentemente esta última no obedece a la ley de lo sucesivo sino que, como en toda representación espacial, ella puede ser concebida en sus diferentes partes simultáneamente. Todas estas observaciones nos permiten ahora comprender adecuadamente el interés y valor que otorgaba $\mathrm{S}$. Weil a las afirmaciones de Kant y Lagneau arriba abordadas. En efecto, la joven S.Weil consideraba, así como Kant y Lagneau, que la configuración espacio-tiempo es la siguiente: si el tiempo es lo que mide el espacio (la cosa medida), aparece también que ese tiempo que mide, para volverse representable a nuestros ojos, necesita ser transpuesto en nuestra existencia como una representación espacial.

\section{Conclusión}

La pesquisa que realizamos en este trabajo nos permitió poner en evidencia cuatro elementos de la concepción del tiempo kantiana que influyeron decisivamente en los primeros análisis de la experiencia temporal que llevó a cabo la joven S.Weil, a saber:

1. el recurso de tomar a Dios como idea reguladora para pensar el tiempo humano;

2. el esquema como instancia de mediación entre nuestro sustrato de comprensión a priori y nuestras experiencias fenoménicas;

3. la preeminencia del tiempo sobre el espacio en tanto que el primero constituye el suelo de intelección del sentido de la realidad y actúa como cimiento de inteligibilidad estructural para medir al segundo -lo medible-;

4. la consideración del espacio como pie de apoyo al que acude la imaginación para representarse el tiempo.

En fin, nuestra investigación nos condujo a discernir que ya en sus primeros años de reflexión, S.Weil comenzaba a perfilar el acercamiento al tiempo que caracterizó a su filosofía madura, y esto a través de dos aspectos: el primero, considerar el tiempo como antagonista de la libertad, o en otras pala- 
bras, como la efectuación misma de la necesidad; y el segundo, y quizá el más importante, sentar las bases de una concepción del tiempo como mediación entre cuerpo y mente. En este sentido, ¿no es acaso el trabajo una segunda mediación que repite y potencia la creación temporal de sentido en el hombre, cuya problematización afloró en la filosofía del trabajo de Simone Weil y que se dibujó clara e intensamente en su obra entre los años 1930-1936?

\section{Bibliografía}

BRISSON, Luc. "Le travail de Simone Weil sur le Timée de Platon". In : Cahiers Simone Weil. Vol. 36, Nr. 3 (Les civilisations inspiratrices), Paris : CNL, 2013. pp. 233-248.

CASPER, Bernhard. "Le temps sauvé". In : Cahiers Simone Weil. Vol. 8, Nr. 3 (Simone Weil et le problème du temps), Paris : CNL, 1985. pp. 240-252.

CHENAVIER, R. "Simone Weil, une philosophie du travail". Paris: Cerf, 2001.

GABELLIERI, E. "Être et don. Simone Weil et la philosophie". Louvain/Paris : Éditions de l'Institut Supérieur de Philosophie Louvain-la-Neuve/Éditions Peeters, 2003.

KANT, I. "Critique de la raison pure". Paris: GF Flammarion, 2001.

KANT, I. "Critique de la raison pratique". Paris: GF Flammarion, 2003.

LAGNEAU, J. "Célèbres leçons et fragments". Paris: PUF,1950.

MARXRER, F. "Avec Simone Weil franchir le rubicon théologique ? Unicité de la croix et pluralité des religions". In Cahiers Simone Weil. Vol. 35, Nr. 1 (Le surnaturel chez Simone Weil), Paris : CNL, 2012. pp. 189-214.

PÉTREMENT, S. "La vie de Simone Weil". Paris: Fayard, 1973.

MIKLOS, V. "La métaphysique religieuse de Simone Weil", Paris : L'Harmattan, 1997. MIKLOS, V. "Kantische Themen im Denken der Simone Weil". In SCHLETTE, Robert/ DEVAUX, A. Simone Weil : Philosophie, Religion, Politik, Frankfurt : Josef Knecht Verlag, 1985.

WEIL, S. “ Du temps" (1929), en CEuvres complètes, TOME I Premiers écrits philosophiques. Paris: Gallimard, 1988.

WEIL, S. 2ème texte, section “APPENDICES", en Euvres complètes, TOME I Premiers écrits philosophiques. Paris: Gallimard, 1988.

WEIL, S. "textes sur le temps et le schématisme", en Euvres complètes, TOME I Premiers écrits philosophiques. Paris: Gallimard, 1988.

WEIL, S. section "Fragments Brefs" en Euvres complètes, TOME I Premiers écrits philosophiques. Paris: Gallimard, 1988.

WEIL, S. "Leçons de philosophie de Simone Weil”, (Roanne 1933-1934), Paris: Plon, 1989.

WEIL, S. "Lette au Père Perrin du 14 mai 1942" -Autobiographie Spirituelle- en Euvres. Paris: Quarto Gallimard, 1999. 